\title{
IMÁGENES PSICOANALÍTICAS Y SOCIALES DE LA ADOLESCENCIA UN COMPLEJO ENTRECRUCE DE AMBIGÜEDADES
}

\section{SOCIAL AND PSYCHOANALYTIC IMAGES OF THE ADOLESCENCE A COMPLEX INTERWEAVING OF AMBIGUITIES}

\author{
ALEJANDRO KLEIN* \\ *Doctor en Trabajo Social. Profesor Investigador de la División de Ciencias Sociales y \\ Humanidades en Campus León, Universidad de Guanajuato. \\ E-Mail: alejandroklein@hotmail.com \\ División de Ciencias Sociales y Humanidades en Campus León, Universidad de Guanajuato. \\ Blvd. Puente Milenio 1001, CP: 37670 León, Guanajuato - México.
}

\section{RESUMEN}

Este trabajo busca ser una contribución al estudio social de la adolescencia tomando como referente de análisis al psicoanálisis de adolescentes. Se plantea que el psicoanálisis de adolescentes no es totalmente homogéneo sino que alberga perspectivas muchas veces contradictorias entre sí. Hay incluso distintas vertientes dentro de los autores estudiados: Winnicott (1972) aportando una visión sociológica del adolescente, Erikson (2009) una visión adaptacionista; Blos (1978) una visión desarrollista, Dolto (1990) una visión antropológica y Aulagnier (1991) una visión historicista. Sin embargo, este cuerpo teórico ha sido fundamental para legitimar y establecer determinadas imágenes de lo que se considera o no adolescente.

Se analizan de esta manera algunos autores (Freud, Anna Freud, Blos, Erikson, Winnicott, otros) desde la perspectiva de intentar comprender las consecuencias de sus opiniones en términos de imágenes psicoanalíticas y sociales. Se privilegian diferentes dimensiones de las mismas (homeostático, anti-homeostático; mesianismo, transgresión; mundo a construir, mundo derrumbándose).
Se podría incluso sugerir que lo que caracteriza estas imágenes adolescentes es lo ambiguo: sexualidad y no sexualidad, actividad y pasividad, seducción y seducido. Ambiguo en el sentido de la imposibilidad de establecer límites definidos entre dichos aspectos, prevaleciendo la continuidad entre ellos más que la ambivalencia o la polaridad nítida entre los mismos.

Se concluye que las imágenes adolescentes son ambiguas, además, porque la propia construcción social del adolescente ha sido altamente compleja y diversa (Klein, 2006), relacionada con múltiples factores sociales. Pero además aparece lo ambiguo desde otra dimensión: se repudia tanto como se desea, se rechaza tanto como se necesita el poder transgresivo y revitalizante de las imágenes adolescentes.

Palabras clave: Adolescencia; Imagen social; Psicoanálisis; Paradoja; Subjetividad.

\section{ABSTRACT}

This paper looks for to be a contribution to the social study of adolescence taking as reference the psychoanalysis of adolescents. It is argued that the 
psychoanalysis of adolescents is not fully homogeneous but contains perspectives often contradictory. There are even different aspects within the studied authors: Winnicott providing a sociological view of adolescents, Erikson an adaptation perspective, Blos a developmental vision, Dolto an anthropological view, and Aulagnier a historicist approach. However, this theoretical framework has been instrumental in legitimizing and establishing certain images of what is or is not adolescence.

As it will be indicated is possible to find a significant swing in the literature on adolescence, from simplified models to others that account an interesting variety of nuances. Freud himself joint both perspectives: from the characterization of nachträglich as psychic process complexity, until the puberty as taming instinctual position on adolescence, his position is wide and open to multiple readings.

Since this perspective are analyzed some authors trying to understand the consequences of their perspectives in terms of psychoanalytic and social images. However there is something that is shared by the cited authors: a great difficulty to understand the adolescents insert within a larger process, involving parents, institutions, society. The bibliography references remains as general feature, from our perspective, in the consolidation of a model of adolescent-type unmarked with social or cultural references, which is, as we shall see, also a decisive adolescent's social image.

Different dimensions of these images are privileged (homeostatic - anti-homeostatic; messianism - transgression; world building - collapse world). It could even suggest that what characterized these adolescents' images is the ambiguity: sexuality and non sexuality, activity and passivity, seduction and seduced. Ambiguous in the sense of the impossibility of establish defined boundaries between these aspects, prevailing the continuity between them, more than the ambivalence or the clear polarity.

Our hypothesis suggests an extension of such analysis, focusing not so much on the binary dualistic but rather in the ambiguous and indeterminate. As developed, the adolescent's images reflect an immense burden of ambiguity between messianism and transgression or between the homeostatic and the anti-homeostatic. There are not clear boundaries between them but rather uncertainty and permanent oscillated passage from one to another image, which simultaneously generates a paradoxical effect: both images are possible without the need to choose one or other.

Adolescence thus becomes necessary to restore the forward sense and the overcome of the difficulties of society. If the disorder becomes something necessary to restore order, this adolescent's image that almost imperceptibly tilts between homeostatic and anti-homeostatic, between been messianism and transgression, represents the aspiration that from barbarism, the unreasonable and uncontrolled, they could be restored civilization, civility and good manners. Adolescence is not only place of loss, the wear of the irretrievable homeostatic economy, but also a vital testing ground on how to stop this transitory madness avoiding the irreversible loss of energy and danger of the world's entry into the age of darkness, apathy or lack of control. The wear of the irretrievable homeostatic economy, but also a vital testing on how to stop this transitory madness avoiding the irreversible loss of energy and the danger of the world's entry into an age of darkness, apathy or lack of control. The adult which each adolescent finally become thus binds to an image of the world.

It is concluded that these adolescents' images are ambiguous also because the social construction of the adolescent is highly complex and diverse, related to social multiple factors. But also appears the ambiguous from another dimension: it repudiates much as desired, is rejected as is required both the transgressive and the revitalizing power of these adolescents' images.

Key words: Adolescence; Social images; Psychoanalysis; Paradox; Subjectivity.

\section{INTRODUCCIÓN}

Se analizan algunas teorías del campo psicoanalítico que han ofrecido aportes valiosos al estudio de la adolescencia. Es necesario que el lector tenga en cuenta que en ocasiones se seguirá con bastante fidelidad las argumentaciones de los autores, pero en otras, las afirmaciones que se utilizarán no 
se desprenderán directamente de los textos citados, sino de referentes sociales o culturales provenientes más de la teoría social, que del campo psicoanalítico. Se mantendrá como pauta general una exposición de las ideas de los autores tanto como una crítica a las mismas, intentando diferenciar las ideas de los autores de aquellas otras referentes al autor del presente ensayo.

\section{DESCRIPCIÓN DE LA ADOLESCENCIA DESDE EL PSI- COANÁLISIS}

Para Giddens, la importancia del psicoanálisis reside en que

"proporciona una panoplia y un rico acervo de recursos conceptuales y teóricos, para la creación de una narrativa reflexivamente ordenada del yo personal y de la identidad personal" (1995, p. 39).

En el caso del psicoanálisis de adolescentes esta observación es por demás acertada. Como se analizará, provee de imágenes con las que la adolescencia es pensada, tanto como facilita el estudio del sujeto adolescente a través de la teoría pubertaria u otras (Klein, 2003, 2004, 2006).

Como se indicará, es posible encontrar una oscilación notable en la literatura consultada sobre adolescencia: desde modelos simplificados a otros que dan cuenta de una diversidad interesante de matices. Freud $(1895,1905)$ mismo reúne ambas perspectivas: desde la caracterización del nachträglich como proceso de complejización psíquica, hasta la pubertad como domeñamiento pulsional, su posición sobre la adolescencia es amplia y está abierta a múltiples lecturas.

Se podría indicar además que no existe probablemente una única teoría psicoanalítica sobre la adolescencia: por ejemplo, la posición de Erikson (2009) parece inconciliable con la de Aulagnier (1991). Una preocupada por los procesos de adaptación del joven a la sociedad, y la otra atenta por establecer un fondo de memoria capaz de otorgar identidad y continuidad psíquica. Hay in- cluso distintas vertientes dentro de los autores estudiados: Winnicott (1972) aportando una visión sociológica del adolescente, Erikson (2009) una visión adaptacionista, Blos (1978) una visión desarrollista, Dolto (1990) una visión antropológica y Aulagnier (1991) una visión historicista.

Sin embargo, si hay algo que comparten los autores citados es una gran dificultad en ver al adolescente inserto dentro de un proceso más vasto, involucrando a padres, instituciones y a la sociedad.

La bibliografía consultada mantiene como rasgo general, desde nuestra perspectiva, la consolidación de un modelo de adolescentetipo sin marcas sociales ni referencias culturales lo que, como veremos, es también una forma decisiva de imagen social del adolescente.

\section{ANÁLISIS DE LAS IMÁGENES ADOLESCENTES DESDE ALGUNAS TEORÍAS PSICOANALÍTICAS}

De cualquier manera y más allá de la diversidad de posturas y matices, creemos poder delinear ciertas imágenes del adolescente, que se recortan sobre el fondo de las teorías psicoanalíticas presentadas. Estas parecen ser básicamente las siguientes:

\section{1.- UN MUNDO EN MOVIMIENTO}

El adolescente aparece como el que permite la consolidación de una biografía, el pasaje de la niñez a la adultez, de lo inmaduro a lo maduro. Refiere de esta manera a un modelo donde las imágenes que se legitiman son las de movimiento: de un adentro a un afuera, de los espacios cerrados a los espacios abiertos, de la familia a la sociedad, de la niñez a la adultez.

Desde el tercer ensayo de Tres Ensayos para una Teoría Sexual, Freud va dando lugar a una imagen del adolescente que comienza a cimentar lo que podría considerarse el imaginario más legitimado de la adolescencia desde el psicoanálisis, la pubertad: 
"Con el advenimiento de la pubertad se introducen los cambios que llevan la vida sexual infantil a su conformación definitiva... La pulsión sexual era hasta entonces predominantemente autoerótica; ahora halla al objeto sexual... La pulsión sexual se pone ahora al servicio de la función de reproducción; se vuelve, por así decir, altruista"(1905, p. 189).

Podría relacionarse también al pasaje de la endogamia a la exogamia, por el cual el adentro se vivencia como un espacio claustrofóbico, cerrado, peligroso, perturbador, contrastando con un afuera público, de todos, lleno de oportunidades y crecimiento. Desde la subjetividad, este movimiento se entenderá como el espacio de lo paterno, la realidad y la ley enfrentado al espacio materno, psicotizante y seductor de lo onírico y lo regresivo (Dor, 1990).

El adolescente está ahí como nexo y garante de abrir los espacios cerrados, de comunicar el afuera con el adentro, de mantener el contacto entre la familia y la sociedad.

El concepto freudiano de conformación definitiva tiene relación con lo normal, lo esperable, lo cerrado e inmodificable, lo que se presenta como necesario e imprescindible, para la conformación adulta definitiva (Klein, 2006).

Nuestra hipótesis es que la preocupación freudiana (y quizás la psicoanalítica posterior) ya no se centra sólo o exclusivamente en lo que sucede en la adolescencia, sino en cuál es el proceso que lleva del niño al adulto. La lógica adolescente se integra a una lógica etárea evolutiva como parte de un proceso de biografía (Klein, 2006). Lo adulto, lo normal, la norma, lo previsible es lo que se pasa a priorizar como objetivo de la adolescencia dentro de una imagen predeterminada del desarrollo.

Desde aquí la imagen de adolescencia que se establece parece que es la de una etapa evolutiva que desde una desregulación energética pubertaria debe ser capaz de lograr regular este exceso de energía recuperando la homeostasis originaria perdida. Creemos que esta idea se enlaza a otra por la cual se establece una primera satisfacción sexual a la que se intenta reencontrar:

"Cuando la primerísima satisfacción sexual estaba todavía conectada con la nutrición, la pulsión sexual tenía un objeto fuera del cuerpo propio: el pecho materno... El hallazgo (encuentro) de objeto es propiamente un reencuentro" (Freud, 1905, pp. 202-203).

Si desarrollamos la hipótesis de que se espera del adolescente una especie de regularización energética podría pensarse que esta imagen es inseparable además de cierto disciplinamiento libidinal. Desde esta perspectiva el adolescente se ve imbuido de tareas mesiánicas y salvadoras.

Blos (1978) parte desde otra perspectiva para replantear una de estas tareas imprescindibles de la adolescencia: sitúa a la adolescencia como un segundo proceso de individuación. Como tal, es un proceso donde existe un colapso pasajero y una reconstitución final de funciones psíquicas (ídem). Es a través de ella que se opera una segunda oportunidad para resolver situaciones abrumadoras de peligro que provienen de la infancia (ídem). La regresión está al servicio del desarrollo: se regresa a lo infantil con una dotación yoica, con más recursos, más polifacética y estable de la que tenía el niño pequeño. A diferencia del niño el adolescente posee, junto al anhelo de gratificación pulsional y yoica una parte del Yo auto-observador y ligado a la realidad que se mantiene intacto, lo que hace que junto a lo regresivo se pase a la conciencia progresiva cumpliéndose una ley epigenética del desarrollo:

"la adolescencia no puede constituir una etapa evolutiva inconclusa. Su final responde a la ley epigenética del desarro1lo. Como todos los otros períodos de la niñez, también la adolescencia pierde su impulso evolutivo, independientemente de que hayan sido cumplidas o no las tareas o desafíos propios de ella. El término de la adolescencia se produce en 
un momento biológico y culturalmente determinado, sea de manera normal o anormal" (Blos, 1978, p. 401).

Se podría entender que la tarea adolescente implica aquí el garantizar la continuidad temporal, estableciendo una secuencia entre pasado, presente y futuro. Desde esta perspectiva el fracaso adolescente implica que permanece lo infantil como un resto anacrónico que conserva conflictos más allá del tiempo y el momento en que debieron haberse solucionado:

"Parece ser una ley del desarrollo que los puntos de fijación de una etapa cualquiera sean trasladados a la siguiente, manteniendo vivo de ese modo el empeño del Yo por armonizar las sensibilidades, vulnerabilidades e idealizaciones que conforman la esencia del self de cada individuo" (Blos, 1978, p. 401).

Nos parece que desde esta imagen la niñez aparece como un proceso que se ha de completar y cerrar para dar lugar a nuevas etapas de la vida, desde un proceso de maduración que se debe completar.

Winnicott (1972) por su parte retomará también la perspectiva de maduración:

"La dinámica es el proceso de crecimiento, que cada individuo hereda. Se da por sentado el ambiente facilitador, lo bastante bueno, que al comienzo del crecimiento y desarrollo de cada individuo es un sine qua non... nada sucede en el crecimiento emocional que no se produzca en relación con la existencia del ambiente, que tiene que serlo bastante bueno. Se advertirá que la palabra perfecto no entra en esta formulación; la perfección tiene que ver con las máquinas, y las imperfecciones que son características de la adaptación humana a la necesidad, constituyen una cualidad esencial del ambiente que facilita" (1972, p. 180).

Nuestra hipótesis es que la perspectiva winnicottiana sugiere que si la sociedad y la familia hacen adecuadamente las cosas (y eso parece ser proporcionar un ambiente facilitador no intrusivo), establecen las condiciones que permiten la expresión del crecimiento como aquello que se concreta gradualmente por fuera de presiones sociales o familiares.

Pero esta imagen de movimiento se puede tomar también desde una dimensión psíquica. De esta manera Aulagnier retoma el tema de la infancia pero dándole una perspectiva nueva pues la ubica como basamento biográfico (1991), desde la cual se da la posibilidad de que el adolescente engendre (auto-engendre) su historia como memoria de un tiempo pasado, pero que continúa existiendo en el presente como anticipación del futuro:

"Es una necesidad de su funcionamiento situarse y anclar en una historia que sustituye un tiempo vivido-perdido por la versión que el sujeto se procura merced a su reconstrucción de las causas que lo hicieron ser, que dan razón de su presente y hacen pensable e investible un eventual futuro" (1984, p. 15).

La infancia funcionaría de este modo generando el número mínimo y necesario de anclajes estables permitiendo una garantía de permanencia, fiabilidad y pudiendo otorgar al adolescente la certeza de poder ser el autor de su propia historia intransferible, desde un tiempo historizado (Aulagnier, 1991). Se trata de una autobiografía anticipando el futuro que nada puede poner en peligro (Aulagnier, 1991), "el yo se abre a un primer acceso al futuro debido a que puede proyectar en él el encuentro con un estado y un ser pasado" (Aulagnier, 1977, p. 169).

El adolescente antes que nada es un historiador que en el ejercicio de este oficio arma una escritura capaz de establecer una ligazón fundamental entre pasado y futuro, estableciendo la infancia como pasado, como causa y fuente de su ser (Aulagnier, 1991), "autoconstrucción continua del Yo por el Yo" (Aulagnier, 1977, p. 167). De allí que la autodeterminación pasa a ser uno de los factores fundamentales de subjetividad. En este 
sentido su pensamiento se acerca al de Urribarri (1990) y al de Jeammet (1992) ya que se trata de indagar cómo se constituye el yo, en tanto espacio interior, inalienable y privado.

Desde esta imagen adolescente habría que destacar que no es lo biológico o la maduración lo fundamental en sí, sino un movimiento psíquico, el après-coup, que permite el establecimiento de un fondo de memoria o referencia identificatoria como incambiable. La referencia a teorías energéticas, económicas, prácticamente desaparece para colocar en primer plano la capacidad del aparato psíquico de generar biografía y anticipar, con especial insistencia en una imagen del adolescente que se construye y autoconstruye.

Freud mismo (1895) indica, a partir del caso clínico Emma, la presencia del nachträglich como una forma de retardo de lo sexual que se vuelve experiencia psíquica:

"Aquí se da el caso de que un recuerdo despierte un afecto que como vivencia no había despertado, porque entretanto la alteración de la pubertad ha posibilitado otra comprensión de lo recordado" (p. 403).

Se trata desde nuestra perspectiva, como en el caso de Aulagnier (1991), de plantear la adolescencia como un movimiento psíquico inédito. La pubertad, a diferencia de la obra de 1905, no es presentada como la sexualidad en sí, ni es el despertar de la sexualidad misma, sino un estado que como señala Laplanche (1980), se encuentra entre lo sexual y lo no sexual, como forma de retardo que "posibilita la ocurrencia de procesos primarios póstumos" (p. 92).

Este retardo es inherente a un mecanismo psíquico esencial: el nachträglich.

"Dondequiera se descubre que es reprimido un recuerdo que sólo con efecto retardado (nachträglich) ha devenido trauma. Causa de este estado de cosas es el retardo de la pubertad respecto del restante desarrollo del individuo" (Freud, 1895, p. 403).
El naghträglich, tomado como sinónimo de pubertad, pone en marcha un proceso de temporalización significativa que sexualiza y en el acto de sexualización engarza, incorpora, crea, acumula psiquismo:

"Si bien en la vida psíquica no es habitual que un recuerdo despierte un afecto que no conllevó como vivencia, eso es algo por entero habitual en el caso de la representación sexual, justamente porque la dilación de la pubertad es un carácter universal de la organización... Toda persona adolescente tiene huellas mnémicas que sólo pueden ser comprendidas con la emergencia de sensaciones sexuales propias" (Freud, 1895, p. 404).

Desde esta perspectiva se podría suponer que la imagen del adolescente se aleja de una visión biologicista, pero podría además sugerirse la hipótesis de que esta imagen adolescente se aparta también de una perspectiva etaria: la adolescencia no es punto de llegada (de la neurosis infantil) ni punto de comienzo (de la edad adulta), sino que presenta una realidad específica difícil de relacionar a términos sociales de adaptabilidad o adultez.

Siguiendo a Laplanche (1980) se podría incluso sugerir que lo que caracteriza a esta imagen adolescente (tal como se retomará en la sección Conclusiones) es lo ambiguo en movimiento: sexualidad y no sexualidad, actividad y pasividad, seducción y seducido. Ambiguo en el sentido de la imposibilidad de establecer límites definidos entre dichos aspectos, prevaleciendo la continuidad entre ellos más que la ambivalencia o la polaridad nítida entre los mismos.

\section{2.- UN MUNDO QUE SE DERRUMBA}

Alude al adolescente como el representante de un mundo que se derrumba lo que genera ansiedad, caos, terror innombrable. De esta manera la adolescencia pasa a implicar, por ejemplo, que la infancia, caracterizada como una mónada llena de energía y poder y ligada a la satisfacción original, 
puede aún así derrumbarse y eventualmente debe dejarse atrás y superarse. Podría pensar que dejar atrás la infancia implica necesariamente un intenso proceso de duelos, tal como indican Aberastury y Knobel a través del síndrome normal de la adolescencia:

"El adolescente atraviesa por desequilibrios e inestabilidad extremas. Lo que configura una entidad semipatológica, que he denominado "síndrome normal de la adolescencia", que es perturbado y perturbador para el mundo adulto, pero necesario, absolutamente necesario para el adolescente, que en este proceso va a establecer su identidad, que es un objetivo fundamental desde este momento vital" (1980, p. 10).

Los duelos que debe enfrentar el adolescente implican pérdidas que se acompañan asimismo de la negación de estas pérdidas, "la angustia y los estados de despersonalización que suelen acompañar a la menstruación como también a la aparición del semen, tienen el significado defensivo de no aceptar que es en el propio cuerpo en el que se están produciendo estos cambios" (Aberastury \& Knobel, 1980, p. 113), lo que lleva a una inestabilidad, agravada por los adultos que no aceptan "las fluctuaciones imprevistas del adolescente sin conmoverse, ya que reedita en los adultos ansiedades básicas que habían logrado controlarse hasta cierto punto" (1980, p. 11). La definición de adolescencia que se ofrece es:

"la etapa de la vida durante la cual el individuo busca establecer su identidad adulta, apoyándose en las primeras relaciones objetales - parentales internalizadas y verificando la realidad que el medio social le ofrece, mediante el uso de los elementos biofísicos en desarrollo a su disposición y que a su vez tienden a la estabilidad de la personalidad en un plano genital, lo que sólo es posible si se hace el duelo por la identidad infantil"' (1980, p. 40).

Desde esta perspectiva nuestra hipótesis es que se ubica al adolescente tanto en un rol mesiánico (permitir que emerja el adulto) como en una posición de desvalimiento (etapa que necesita cuidados). Más allá de la clara impronta biologicista que implican los duelos, parecen indicar la idea de que ningún niño desea dejar de ser niño. La infancia se establece como una edad dorada, paradisíaca y nostálgica. El adolescente repite aspectos de esta infancia y por otra parte, se ve obligado a ser adolescente: la adolescencia surge como forzamiento, invasión, ataque. En este sentido nunca se es adolescente en tiempo y forma (Klein, 2004).

De alguna manera el síndrome normal de la adolescencia reedita a su vez (o es una nueva versión) del concepto de moratoria de Erikson (Maier, 1980): un espacio de tolerancia a las extravagancias del joven. En ambos casos operando teleológicamente por el logro de la identidad y la inserción al mundo adulto. Dejar la infancia es, según parece, como ser expulsado de la misma. Y aún expulsado, la persistente negación del cambio puberal señala la compulsión del deseo de volver a la misma.

Esta actitud sospechosa se repite, a su vez, en relación a la sociedad, acusada de aprovecharse del adolescente y su vulnerabilidad. Se entiende que la figura del chivo emisario (Pichon-Riviére, 1981) podría tomarse como una variante de esta imagen. De allí que sea impensable, desde este tipo de imagen, una posición activa, triunfante, victoriosa del adolescente ante su propia adolescencia ${ }^{1}$.

1 Estas ideas fueron analizadas y criticadas por Urribarri (1990) para quien se ha hecho un mayor énfasis en lo que se pierde, en detrimento de lo que se desarrolla en esta etapa de la vida. Lo que lo lleva a hacer una serie de precisiones y críticas en torno a la teoría de los duelos que implican observaciones críticas que Urribarri lleva delante de forma perspicaz. Su trabajo ejemplifica además una nueva tendencia inaugurada por Aulagnier (1991) y seguida por Jeammet $(1989,1992)$ y Kancyper (1992, 1997) preocupada por establecer nuevas bases o fundamentos a la teorización sobre la adolescencia. 
Podría pensarse que desde la caída de la infancia, cualquier otro orden de cosas, como el social puede agonizar: si ya nada se sostiene, ya nada es seguro. El valor de peligro se combina simultáneamente con la fascinación de un ser que se puede metamorfosear, regenerando y revitalizando en el mismo acto, al mundo todo y al sujeto mismo.

De esta manera esta imagen del adolescente no puede sino movilizar la ansiedad frente a la posibilidad del cuestionamiento de la base de nuestra identidad y las certezas más arraigadas.

Más adelante, se sugerirá que se trata además de una imagen que incluye la pregunta angustiante de cómo las fuerzas del orden se pueden conjugar para contrarrestar las fuerzas del desorden y cómo -al mismo tiempo- este desorden no puede dejar de acechar permanentemente en la forma paranoica de lo disruptivo, lo adolescente, el peligro, la enfermedad, lo virósico.

\section{3.- UN MUNDO NECESITADO DE PROTECCIÓN}

Es una imagen que alude a la vulnerabilidad del adolescente, su desamparo por portar una piel renovada. Es decir, se trata de imágenes uterinas, neonatales, de permuta, de recambio de piel y psiquismo. Dolto (1990) es una conspicua autora que presenta a la adolescencia desde este enfoque de vulnerabilidad o en términos winnicotttianos: la necesidad de cuidar de un self verdadero. El crecimiento, insiste Winnicott, no se puede dirigir ni es adaptación. En su lugar se debe destacar lo impredecible y lo espontáneo que son una forma de protección del self adolescente (Winnicott, 1981):

"Otra fuente de confusión es la voluble suposición de que si las madres y los padres crían bien a sus bebés y niños, habrá menos problemas. ¡Lejos de ello!... deseo sugerir que cuando estudiamos la adolescencia, en la cual los éxitos y fracasos del cuidado del bebé y el niño empiezan a ser empollados, algunos de los problemas actuales se relacionan con los elementos po- sitivos de la crianza moderna y de las actitudes modernas respecto de los derechos del individuo" (Winnicott, 1972, p. 185).

En este sentido creemos que Winnicott no cree en los logros de la adaptabilidad sino más bien en las posibilidades del crecimiento desde el self verdadero. El crecimiento es lo prioritario, todo se subordina a él. Pero el crecimiento implica a su vez una agresividad confrontante que también ha de ser cuidada y protegida con el nombre de sobrevivencia:

"Si se hace todo lo posible para promover el crecimiento personal de los descendientes, habrá que hacer frente a resultados sorprendentes. Si sus hijos llegan a encontrarse a sí mismos, no se conformarán con encontrar algo, sino que buscarán la totalidad, y ello incluirá la agresión y los elementos destructivos que existen en ellos, tanto como los que se pueden denominar amantes. Y se producirá esa larga pendencia a la que habrá que sobrevivir" (Winnicott, 1972, p. 185).

Pavlovsky (1975) desde un ángulo clínico acompaña también esta perspectiva. El autor indica que el encuadre con adolescentes es el que crea las condiciones necesarias para contener su crisis, por lo que se hace necesario e imprescindible el establecimiento de un "vínculo suficientemente estable y seguro con el equipo terapéutico" (p. 27). El adolescente necesita:

"un continente suficientemente sólido para poder dialogar... estamos sometidos a prueba permanentemente: el adolescente no se comunica si no se siente seguro de ser comprendido; y ser comprendido significa para él tener la seguridad de ser entendido en el mundo caótico de su crisis" (p. 27).

Ya no se trata de la confrontación, como señalan Winnicott (1972) y Kancyper (1997), sino de confianza: el adolescente es un ser al que hay que demostrarle que el adulto es un 
ser confiable, bueno, esperanzador, estimable. No hay ni tiene que haber conflicto con el adolescente, del cual hay que esperar lo mejor y el que tantea si existe un auténtico interés por comprender lo que él dice. Se trata según Pavlovsky (1975), de un paso pre-interpretativo: asegurarse si comprendemos lo que nos dice, "necesidad imperiosa....de saber si lo estamos entendiendo o no" (p. 28).

De allí la sugerencia de una técnica más activa a través de preguntas, diálogos espontáneos:

"Esta actitud más simétrica (y menos omnipotente) contornea la silueta de un rol terapéutico que interviene en la sesión no sólo interpretando, sino por un modo personal de participar, de sentir, de convivir, de aceptar, de rechazar, de reír o de angustiarse, etc., en la sesión" (Pavlovsky, 1975, p. 29).

Se trata, desde nuestro análisis, de consolidar el sentido de la buena fe: el adulto debe y puede comprender en todo momento al adolescente Los fracasos se retraducen en la incapacidad o perspectiva errónea del adulto, lo que señala una perspectiva culpabilizante. El presupuesto de Pavlovsky parece ser el de la naturaleza bondadosa del adolescente. Basta un ambiente confortable y creativo para que el mismo mejore o se reponga (semejante a las ideas de Winnicott, 1972). Se trata de favorecer un clima natural y de franca espontaneidad, modificando el rol terapéutico:

"Nuestra preocupación actual es la "desmitificación del rol terapéutico"; nuestra experiencia concreta nos ha mostrado que las deserciones en los grupos disminuyeron cuando modificamos nuestra actitud terapéutica. Cuando transformamos el silencio en diálogo; cuando nos animamos a hacer preguntas sin temor; cuando fuimos más espontáneos; cuando cambiamos la "magia del clima de misterio del grupo" en una simple conversación entre pacientes y terapeutas; cuando fuimos más personas y nos incluimos con nuestras propias dudas e incertidumbres; cuando estuvimos más "cerca" del adolescente, rompiendo la barrera artificiosa entre "ellos y nosotros"; en otras palabras, cuando todo el proceso terapéutico se humanizó" (Pavlovsky, 1975, p. 36).

De esta manera se cree que aparece la imagen de un adolescente bienintencionado, que requiere de adultos buenos y serviciales. El adolescente aparece con una naturaleza genuina y bondadosa dentro de lo que será desarrollado más adelante como imagen mesiánica y homeostática.

Si se piensan estas imágenes desde una perspectiva religiosa se podría esbozar la hipótesis que aluden a la muerte y la resurrección y que ambos confluyen en un sentido mesiánico y salvador: la figura de Jesús entre el calvario y el ascenso a los cielos, imagen nostálgica y optimista de un nuevo mundo en gestación (Klein, 2006). Desde esta imagen el terapeuta se ubica lleno de conmiseración, anhelo y empatía frente a este paciente llamado a ser el chivo expiatorio - emisario de la humanidad. Estas imágenes parecen postular un psicoanálisis que acoge y defiende a una adolescencia huérfana y olvidada por la sociedad, desde una postura protectora que podría entenderse también como una preocupación por establecer procesos reparatorios y curativos.

\section{4.- UN MUNDO A DISCIPLINAR}

La imagen del adolescente que presenta Erikson, Anna Freud o Freud mismo lleva implícito la necesidad de un mundo a ser disciplinado. Esta imagen se traduce en términos psicoanalíticos como una infancia (que bien podría considerarse mítica) con una homeostasis regulada y auto-regulada a la cual la pubertad viene a desregular y desequilibrar a través de instintos descontrolados (Freud, A., 1985). Se trata de un mundo que incomoda y al cual hay que disciplinar y subordinar (Barrán, 1995), para alcanzar fi- 
nalmente la integración ${ }^{2}$ y la reinstauración del orden y la homeostasis.

Podría pensarse, como enseguida se desarrollará, que este Yo amenazado es además una metáfora de una sociedad adulta que a su vez se siente amenazada y atacada desde dentro por algo que es disruptivo (y que se deposita en la adolescencia) y lo que hay que adultizar y controlar.

\section{AMPLIACIÓN DE LAS IMÁGENES ADOLESCENTES HA- CIA UNA PERSPECTIVA SOCIAL}

A grandes rasgos y simplificando se podrían plantear dos grandes grupos imagógicos:

\section{1.- EL ADOLESCENTE ENTRE LA HOMEOSTASIS Y LO ANTI-HOMEOSTÁTICO}

La imagen de un mundo en peligro de derumbe se podría ampliar y complejizar desde la perspectiva de lo anti-homeostático versus lo homeostático. Lo anti-homeostático se relaciona con la primera imagen peligrosa asociada al adolescente en la modernidad: el onanismo (Barrán, 1995). La masturbación aparecía como el paradigma del descontrol físico y psíquico, que amenazaba y confirmaba la enfermedad del adolescente:

“irreflexiva entrega del cuerpo y el alma a los placeres sexuales que llega a cono-

2 Los errores freudianos en lo que respecta a la sexualidad femenina (Burin \& Meler, 1998; Dio de Bleichmar, 1997), se podrían repensar también como una tentativa de integración. Homologar el clítoris al pene y la sexualidad femenina a lo masculino hace que la mujer dependa para su adolescencia, de las vicisitudes de lo masculino de su libido. Nuestra hipótesis es que la preocupación por lo unificado lleva a que lo masculino, como fuerza primordial de la libido transforme en secundario todo lo que tenga que ver con lo femenino. Se repite de esta manera el esquema de subordinación, ya no entre lo pre-genital y lo genital, sino de lo femenino hacia lo masculino. cer antes de ser apto a las nobles funciones" (1995, p. 61).

Se consideraba al onanismo una pérdida inútil de energía tanto como un ataque al cuerpo frente al cual la sociedad se sentía paranoicamente expuesta y en situación de peligro delante de una práctica onanista que se consideraba un enfermizo cuestionamiento de la descendencia y la familia. El adolescente quedaba ubicado como "una naturaleza de por sí enferma que convocaba todos los cuidados y vigilancias de las autoridades sociales" (1995, p. 61).

Quedaba así establecido un enemigo social: el deseo irrefrenable y compulsivo. Y su agente-responsable, el adolescente, por lo que frente a esta digresión se imponía el control:

"Todas estas disciplinas...buscaban crear hábitos de obediencia a las órdenes "lógicas" de la salud que luego se convertirían en hábitos de obediencia a las órdenes "lógicas" de la sociedad y el orden establecido. Lo esencial era someter al "capricho", combinación peligrosa del deseo con la voluntad rebelde" (1995, pp. 59-60).

Esta masturbación adolescente tan temida genera la imagen de un cuerpo (y una sociedad) como fortalezas asediadas por la intrusión interna de una sexualidad, virulenta, avasallante y anti-homeostática. Frente a la misma se contrapone un proyecto homeostático de salud que se apoya en la contención, el ahorro, la discreción y la pureza ${ }^{3}$.

\footnotetext{
${ }^{3}$ Hago la observación -sin poder desarrollarla- de que la sintaxis del Novecientos, no ha perdido un ápice de su eficacia: así como antes la masturbación idiotizaba, enloquecía y mataba, ahora se desplazan los mismos efectos a la droga. Los cuadros descriptivos de decadencia física, dejadez y decadencia moral utilizados para los masturbadores de antaño se reciclan y son similares a algunas descripciones (tan científicas como las de aquella época) utilizadas para los consumidores de droga.
} 
Pensamos que si Freud (1905) muestra a la pubertad como un proceso disciplinador y doblegador, es porque se presenta quizás a lo pregenital como lo indomable y caótico. Su sujeción en lo genital asegura -suponemoslo organizado, lo racional, lo comprensible, desde el pasaje de lo autoerótico a lo heterosexual, del desborde a la unificación, de lo caótico a lo adaptativo. La hipótesis es que esta imagen del adolescente termina por recordar la de un organismo capaz de transformar el exceso de energía hacia un equilibrio homeostático que es siempre de alguna manera re-equilibrio, ya que remite a la satisfacción original: la perspectiva psicológica es absorbida por una perspectiva biologicistaenergética.

Ideal de un cuerpo (y una sociedad) basados "en un aprendizaje gestual común (que permite) una transparencia social en la que (la sociedad) ve la condición previa necesaria para la realización de una sociabilidad generalizada" (Ariès \& Duby, 1990a, p. 173).

Se impone así la imagen de un cuerpo adolescente casto, adulto, renunciante, indicando el restablecimiento de la homeostasis como un máximo fin.

Una de las variantes de esta homeostasis triunfante sobre la anti-homeostasis la presenta A. Freud desde otro ángulo. Para la autora el adolescente, al igual que la persona que pasa por un infortunio amoroso, atraviesa un intenso período de duelo (Freud, A., 1985). Este duelo es el que hace que los adolescentes, a pesar del sufrimiento y el deseo de ayuda, no respondan bien a la terapia:

"Son estados emocionales en los que la libido del individuo está totalmente comprometida con un objeto de amor real del presente o del pasado inmediato; el dolor mental es el resultado de la difícil tarea de retirar la catexia y renunciar a una posición que ya no ofrece posibilidades de retorno del amor; es decir de gratificación. Mientras el individuo se encuentra empeñado en esta lucha no dispone de libido suficiente para catectizar la persona del analista... para que la terapia resulte eficaz es necesario que el paciente renuncie antes a su objeto inmediato de amor y de duelo" (Freud, A., 1985, p. 172).

La hipótesis es que en lo que en S. Freud aparecía como una metáfora de pasaje de lo insubordinado a lo subordinado, en A. Freud se transforma en una metáfora de las experiencias decisivas que hacen a la diferencia entre locura y normalidad. Si la pubertad era en aquel la desregulación de una regulación energética, en A. Freud parece tratarse de la pubertad como un momento de locura transitorio, que es a su vez el medio de consolidar la estabilidad mental del adulto:

"...la salud mental se basa en última instancia en la armonía” (1985, p. 183).

La perturbación del adolescente se vuelve entonces beneficiosa y necesaria en tanto permite regular las modificaciones cualitativas de la pubertad. Mientras la latencia se caracteriza por el orden y la orientación social, la pubertad lo hace por el descontrol y el desorden. La imagen de la adolescencia que se cree que surge es la de una etapa capaz de restablecer un equilibrio que dará lugar a una personalidad adulta garantizando la normalidad mental.

Para restablecer este equilibrio se genera un campo de lucha entre tendencias opuestas. Por un lado, el Yo organizador y garante de la genitalidad adulta; por el otro el Ello, centro del desborde, de las fuerzas ciegas, del egoísmo y la rebeldía contra metas sociales. Aquél, con una homeostasis regulada y autoregulada; éste, des-regulante y des-equilibrante, descripto dentro de una imagen que parece ser de revuelta y conspiración, en la cual los instintos descontrolados son armas usadas contra la armonía de la niñez y la adultez.

Nos hace pensar que se trata de un Yo amenazado y atacado desde dentro por lo puberal, peligro que se conjura por una serie de etapas que aseguran el pasaje de la niñez a la adultez, de lo disgregado a lo congregado, de 
la perversidad infantil a la responsabilidad reproductiva adulta. Es una imagen que parece transmitir una ideología de la adaptación evitando excesos y a los desbordes. Pero esta lucha entre el Yo y el Ello también se podría replantear como un conflicto entre individuo y sociedad, entre la nostalgia narcisista y la obligación y el decoro social.

De esta manera esta temerosa imagen antihomeostática se consensúa aparentemente desde dos perspectivas. En una de ellas, la sociedad aparece positivamente constituida por miles de familias a la manera de átomos-células encargadas de la educación y la sociabilidad; en la otra, se opone en negativo la imagen de un germen u organismo invasor atacante encarnado por el adolescente, quien a su vez, también es atacado internamente por el organismo devastador de la sexualidad pubertaria (Klein, 2006).

La hipótesis es que se legitima así la naturalización de un doble proceso: así como la adolescencia es invadida por un cuerpo pubertario descontrolado, heteróclito, irregular, el adolescente se comporta a su vez rebelde y hetero-cinésicamente con respecto a su familia y la sociedad.

Si la hipótesis de que la modernidad genera y mantiene estos fantasmas que la desvelan y fascinan es correcta (Ariès \& Duby, 1990c) hay que tener en cuenta que este proceso es indisociable de su depositación en la adolescencia, haciendo del adolescente la personalización y el emergente (Pichon-Riviere, 1981) de procesos anti-homeostáticos que sintetizan lo incomprensible e innombrable del terror ante el cambio y lo imprevisto (tanto en lo social como en lo personal).

Pero como vimos, lo anti-homeostático admite también su contrario: una imagen homeostática. Aquí al adolescente se lo sitúa más cerca de lo conservador, de la reminiscencia, la nostalgia y la valorización de un pasado personal y social.

Algunas de las transgresiones adolescentes se reinterpretan desde este ángulo imagógico no como destrucción al mundo, sino como una disconformidad por un mundo corrupto al que se compara con otro mejor, más justo o más protector ${ }^{4}$. Es un mundo necesitado de protección que alude asimismo a la imagen optimista de un nuevo mundo en gestación.

El adolescente se vuelve desde esta perspectiva capaz de procrear un mundo nuevo:

"con mucha frecuencia constituye la figura nostálgica de una organización comunitaria que excluía el secreto, el aislamiento y la constitución del espacio privado" (Ariès \& Duby, 1990a, p. 386).

La adolescencia aparece de esta manera, como el depósito de cierta moralidad sana, honesta y profunda.

Se podrían ubicar aquí por ejemplo, las imágenes fílmicas del adolescente romantizado y contestatario (Rebelde sin Causa), las del adolescente ético y puro (El Graduado) y las del adolescente de la nueva era (Woodstock). El adolescente pasa a ser ahora el cuidador y preservador homeostático de la sociedad. Presentado como guardián moral se lo hace detentador de los valores más puros, sacros y ejemplificantes, alejados de las renuncias morales de los adultos.

\section{2.- EL ADOLESCENTE ENTRE EL MESIANISMO Y LA TRANSGRESIÓN}

Los rasgos reconstructores que se le aplican al adolescente son inseparables de un carácter mesiánico y reparador. Pero en la medida en que se lo vuelve capaz de forjar un nuevo mundo se hace inevitable la imagen contradictoria de transgresión, ya que para construir debe necesariamente fragilizar (re-

\footnotetext{
4 La imagen que se tiene del movimiento hippie (por ejemplo) intrincado a una actitud ecologista, que busca la restauración de una naturaleza que no haya sido malherida, mutilada, castigada y a través de ella, la reinstauración de formas comunales de convivencia y solidaridad. Proceso que implica el retorno a la madre naturaleza y a un paraíso perdido potenciando la vuelta a lo genuino, lo real y esencial.
} 
cuérdese la imagen diabólica de la sexualidad) los vínculos sociales y familiares.

La imagen de masturbación (Barrán, 1991; Foucault, 1995) que conlleva una práctica solitaria que desdeña o ignora al otro implica transgresivamente una práctica no reproductiva, asentada en el secreto y la intimidad para erigir un espacio de opacidad. En la medida que la burguesía del Novecientos transforma el dispositivo de sexualidad en una intensificación y problematización del cuerpo, la vida y la salud (Barrán, 1991; Foucault, 1995), esta imagen adolescente onanista no puede sino despertar temores y rechazo al interpretársela como extinción de la transmisión generacional.

La imagen del adolescente vacila de esta manera entre la instauración de un nuevo orden (mesianismo) y la destrucción de uno antiguo (transgresión). Esta ambigüedad podría explicar tanto el poder de fascinación de la adolescencia, como la vivencia de peligro que despierta. Representa un ideal a construir tanto como un ideal a temer ${ }^{5}$.

Al hacerlo responsable de cambios la imagen que se impone es la del chivo emisarioexpiatorio (Pichon-Rivière, 1981). El adolescente derriba el orden social (o sea: tiene una función desligante-tanática) tanto como se encarga de construir un mundo nuevo (o sea: tiene una función ligante-erótica) (Klein, 2003).

Quizás el mejor representante de esta imagen constructiva-mesiánica sea Erikson, el que insiste en la consideración de los cambios constitucionales y aprendidos (2009), dentro de una progresiva integración secuencial, que va desde el recién nacido al anciano, pasando por la adultez y la adolescencia. Las ocho etapas epigenéticas del desarrollo que Erikson describe, integran diversos aspectos culturales y psíquicos mien-

5 Según Durkheim, todo aquello que tiende al ideal se asocia a un estado de confianza, de alegría y aun de entusiasmo. En tanto ideal temido, su imagen se acerca a los ritos de expiación, la pena, al miedo, la tragedia (Nisbet, 1996). tras que la conmoción (¿lo conflictivo?) pasa a ser lo transitorio y superable.

Este principio optimista parece que le permite augurar a Erikson una rápida inserción del adolescente a la sociedad atenuando los factores de conflicto (Erikson, 2009). El eje es la adaptación ${ }^{6}$ y su teoría sobre la adolescencia se enlaza a la necesidad de la consolidación yoica:

"El individuo que se desarrolla se esfuerza por alcanzar la unidad, depositando su confianza en un pasado y un futuro continuos y en su identidad con ambos... la maduración corporal halla su contraparte emocional en el desarrollo de la personalidad" (Maier, 1980, p. 27).

La relación entre el adolescente y la sociedad es entonces de reconciliación y creatividad. En Youth and Crisis Erikson plantea:

"No podemos separar el crecimiento personal del cambio social... ni podemos separar... la crisis de identidad en el desarrollo histórico, porque los dos aspectos contribuyen a su mutua definición, y realmente dependen uno de otro" (Maier, 1980 , p. 23).

Erikson (2009) indica que la adolescencia presenta una moratoria psicosocial como forma de autorización social que implica un recurso psicológico de seguridad. Se trata de moratorias institucionalizadas como educación prolongada, conscripción militar, el internado u otros, que aseguran un tiempo que

\footnotetext{
6 Pero a su vez, si el desarrollo es integración y la integración un proceso donde sobresale la triple integración: del cuerpo y la mente, de la mente y la identidad, de la identidad y la sociedad, creemos entonces que no hay lugar para el conflicto. Se trata quizás del mismo interrogante que se podría plantear a A. Freud: ¿cómo una teoría del orden y la integración, puede dar cuenta de una adolescencia desordenada y transgresora?
} 
se considera necesario de crecimiento e integración social. En definitiva,

“...el individuo necesita tiempo para integrarse en la edad adulta y la sociedad se lo concede" (Maier, 1980, p. 70).

La imagen de la adolescencia que parece transmitir es que la misma debe restaurar y mantener un principio de confianza e integración entre lo social y el individuo. El adolescente es el gran integrador entre pasado y futuro, niñez y adultez, individuo y sociedad. Y además se debe integrar a una tarea $u$ ocupación. La principal tarea del adolescente es resolver (con la ayuda de la sociedad) su adolescencia a través de su plena inserción a la sociedad. Nuestra hipótesis es que dentro de esta imagen el fin de la adolescencia sería el ciudadano, asegurando un mundo confiable, una democracia vigorosa, una sociedad en tal sentido integrada (Klein, 2006).

\section{Conclusiones}

Cabe preguntarse en primer lugar si las imágenes señaladas de la adolescencia se podrían incluir dentro de lo que se plantea como representaciones hegemónicas sociales, en tanto las mismas "disputan la producción del sentido a las representaciones alternativas ya que existen diversos sectores dentro de una cultura compleja" (Burin \& Meler, 1998, p. 31).

Desde el psicoanálisis mismo, el clásico trabajo de Anthony desarrolla la hipótesis de una prevalencia de estereotipos hegemónicos de la adolescencia en relación a lo amenazante, sexualizado, envidiado, entre otros (Burin \& Meler, 1998). El análisis de Anthony es de tipo binario y probablemente tal divalencia refleja una referencia a la teorización kleiniana: el adolescente despierta sentimientos de envidia y muerte desde una concepción objeto buenoobjeto malo (Baranger, 1971).

Nuestra hipótesis sugiere una ampliación de tal análisis, enfocándolo no tanto en lo binario dualístico sino más bien en lo ambiguo e indeterminado. Como se ha desarrollado, las imágenes adolescentes reflejan una inmensa carga de ambigüedad entre mesianismo y transgresión o entre lo homeostático y lo anti-homeostático. No parecen existir entre ellos límites claros sino más bien indeterminación y pasaje oscilante permanente de una a otra imagen, lo que al mismo tiempo genera un efecto paradojal: ambas imágenes pueden ser posibles sin que haya necesidad de escoger una $u$ otra.

Las imágenes adolescentes son ambiguas, además, porque la propia construcción social del adolescente ha sido altamente compleja y diversa (Klein, 2006), relacionada entre otros factores a

"una multiplicidad de elementos discursivos que pueden actuar en estrategias diferentes" (Foucault, 1995, p. 122).

Pero además está en juego también lo ambiguo desde otra dimensión: se repudia tanto como se desea, se rechaza tanto como se necesita el poder transgresivo y revitalizante de las imágenes adolescentes.

La prevalencia social de lo pubertario ha operado como un dispositivo mítico que ha legitimado el que todos, en tanto seres humanos, pasamos por la pubertad. Lo que la convierte en una situación universal, homogeneizadora y desvinculada totalmente de cualquier contexto o situación particular. Como depositaria de los dramáticos cambios de la edad se localizan en la pubertad fuerzas descontroladas y salvajes frente a las cuales se hace necesario racionalizar, re-controlar y organizar adultamente el pasaje de lo disruptivo sexual a lo adaptado social.

Además, si el desorden, el cambio, el caos, lo aleatorio, se personalizan (como adolescencia) y pasan a ser una etapa etaria, se consolida la idea de que toda disrupción, aunque deba ser aceptada, conserva su carácter transitorio. Si pensamos en lo que se espera de cada persona, de lo lógica y socialmente esperable, todos pasamos de ser revoltosos a ser responsables, de ser púberes adolescentes a adultos. El desorden transitorio se ordena y se reinstaura la normalidad permanente consolidándose el pasaje de la adolescencia a la 
adultez. Todo desorden (sea éste personal o social) se vuelve, necesaria y tranquilizadoramente, transitorio.

La adolescencia se vuelve así imprescindible para restaurar el sentido de avance y de superación de las dificultades de la sociedad. $\mathrm{Si}$ el desorden se transforma en algo necesario para restaurar el orden (Ariès \& Duby, $1990 \mathrm{~b}$ ), esta imagen adolescente que bascula casi imperceptiblemente entre lo homeostático y lo anti-homeostático, entre el mesianismo y la transgresión, representa la aspiración que desde la barbarie, lo irrazonable y el descontrol, se restauren la civilización, la urbanidad y las buenas maneras. El adulto al cual finalmente cada adolescente advendrá se enlaza de esta manera a una imagen disciplinada del mundo.

Ya Ariés y Duby (1990b) señalaban que:

"la función de la existencia juvenil es hacer que disuenen las reglas sociales moviéndose constantemente en los límites de lo tolerable" (pp. 168-169).

Pero es un punto de vista incompleto si no se advierte que la adolescencia no es solo un lugar de la pérdida, del desgaste, de lo irrecuperable de la economía homeostática, sino también un campo de experimentación vital sobre cómo detener esa locura transitoria evitando la pérdida irreversible de energía y el peligro de la entrada del mundo en la era de la oscuridad, la apatía o el descontrol.

Finalmente es necesario plantear una observación epistemológica: ¿acaso es imposible hablar del adolescente sin recurrir al discurso que la sociedad se forja sobre él? ¿O es que imagen social y dato empírico - clínico se hacen por momentos indistinguibles en el caso de la adolescencia? Por un lado es posible observar que la adolescencia en sí misma es ambigua en tanto remite a complejos procesos de construcción de identidad, reafirmación sexual, nuevos vínculos y nuevas inserciones institucionales, entre otros factores de constitución de subjetividad (Klein, 2003, 2006). Por otro, a la tradicional y evasiva discreción del adolescente se agrega el apabullante clamor de estos discursos por y desde los cuales el adolescente es discurseado. Discursos que nos revelan las obsesiones, las paranoias, los deseos de una sociedad fascinada en haber encontrado en este adolescente un emisario y un depositario de sus fantasías y proyecciones, tanto como el espejo de sus anhelos y frustraciones (Klein, 2006).

\section{REFERENCIAS BIBLIOGRÁFICAS}

Aberastury, A. \& Knobel, M. (1980). La adolescencia normal. Un enfoque psicoanalítico [The normal adolescence. A psychoanalytical approach]. Buenos Aires: Paidós.

Ariès, P. \& Duby, G. (Org.) (1990a). El proceso de cambio en la sociedad de los siglos XVIXVIII. En P. Ariès \& G. Duby (Eds.), Historia de la vida privada [History of the private life]. Tomo 5. Argentina: Ed. Taurus.

Ariès, P. \& Duby, G. (Org.) (1990b). La comunidad, el estado y la familia. En P. Ariès \& G. Duby (Eds.,), Historia de la vida privada [History of the private life]. Tomo 6. Argentina: Ed. Taurus.

Ariès, P. \& Duby, G. (Org.) (1990c). Sociedad burguesa: Aspectos concretos de la vida privada, En Ariès, P. \& Duby, G. (Eds.), Historia de la vida privada [History of the private life]. Tomo 8. Argentina: Ed. Taurus.

Aulagnier, P. (1977). La violencia de la interpretación. Del pictograma al enunciado [The interpretative violence. From pictogram to statement]. Buenos Aires: Amorrortu.

Aulagnier, P. (1984). El aprendiz de historiador y el maestro brujo. Del discurso identificante al discurso delirante [The apprentice of historian and the master sorcerer. From the identifier discourse to the delirious discourse]. Buenos Aires: Amorrortu. 
Aulagnier, P. (1991). Construir (se) un pasado [Build (himself) a past]. Revista de PAAP de BA, 13(3), 441-468.

Baranger, W. (1971). Posición y objeto en la obra de Melanie Klein [Position and object in the work of Melanie Klein.]. Argentina: Kargieman.

Barrán, J. (1991). Pubertad y adolescencia, una visión histórica uruguaya: Del ochocientos al novecientos [Puberty and adolescence, a historical uruguayan view: From the eighteen to nineteen]. En J. Portillo et al. (Eds), La adolescencia. Montevideo: Editorial de la Banda Oriental.

Barrán, J. (1995). Medicina y sociedad en el Uruguay del novecientos. Tomo 3, La invención del cuerpo [Medicine and society in the Uruguay of the nineteen's. Book 3. The invention of the body]. Montevideo: Editorial de la Banda Oriental.

Bleichmar, N. \& Bleichmar, C. (1999). El psicoanálisis después de Freud. Teoría y clínica [The psychoanalysis after Freud. Theory and clinic]. México: Paidós Ibérica.

Blos, P. (1978). La transición adolescente [The adolescence transition]. Buenos Aires: ASAPPIA.

Burin, M. \& Meler, I. (1998). Género y familia. Poder, amor y sexualidad en la construcción de la subjetividad [Gender and family. Power, love and sexuality in the construction of subjectivity]. Buenos Aires: Paidós.

Dio Bleichmar, E. (1997). La sexualidad femenina. De la niña a la mujer [The female sexuality. From child to woman]. Barcelona: Paidós.

Dolto, F. (1990). La causa de los adolescentes [The cause of the teenagers]. España: Seix Barral.

Dor, J. (1990). El padre y su función en psicoanálisis [The father and his function in psychoanalysis]. Buenos Aires: Nueva Visión.
Erikson, E. (2009). Infancia y sociedad [Childhood and society]. Buenos Aires: Horme Paidós.

Foucault, M. (1995). Historia de la sexualidad 1. La voluntad de saber [History of the Sexuality - 1. The will to know]. Madrid: Siglo XXI.

Freud, A. (1985). Psicoanálisis del desarrollo del niño y el adolescente [Psychoanalysis development of children and adolescents]. Buenos Aires: Paidós.

Freud, S. (1895). Proyecto de una Psicología para neurólogos [Project of one Psychology for neurologists]. Buenos Aires: Amorrortu.

Freud, S. (1905). Tres ensayos de teoría sexual [Three essays on the theory of sexuality]. Buenos Aires: Amorrortu.

Freud, S. (1913). Tótem y tabú [Totem and taboo]. Buenos Aires: Amorrortu.

Giddens, A. (1995). La transformación de la intimidad. Sexualidad, amor y erotismo en las sociedades modernas [The transformation of intimacy: Love, sexuality, and eroticism in modern societies]. España: Ediciones Cátedra.

Jeammet, P. (1989). La depresión en el adolescente [Depression in the adolescent]. En S. Lebovici, R. Diatkine \& M. Soul (Eds.), Tratado de Psiquiatría del niño y el adolescente. Tomo III. España: Editorial Biblioteca Nueva.

Jeammet, P. (1992). Lo que se pone en juego: Las identificaciones en la adolescencia [What is relevant: The identifications in adolescence]. Revista de Psicoanálisis $N$ y A, 2. Buenos Aires: Impresión El Llibro SRL.

Kancyper, L. (1992). Resentimiento y remordimiento - Estudio psicoanalítico [Resentment and regrets. Psychoanalytical study]. Buenos Aires: Paidós.

Kancyper, L. (1997). La confrontación generacional [The generational confrontation]. Buenos Aires: Paidós. 
Klein, A. (2003). Escritos psicoanalíticos sobre psicoterapia, adolescencia y grupo [Psychoanalytic writing on psychotherapy, adolescence and groups]. Uruguay: Psicolibro Waslala.

Klein, A. (2004). Adolescencia, un puzzle sin modelo para armar [Adolescence: A puzzle without a model for solving]. Uruguay: Psicolibro, Waslala.

Klein, A. (2006). Adolescentes sin adolescencia: Reflexiones en torno a la construcción de subjetividad adolescente bajo el contexto neoliberal [Adolescents without adolescence: Reflections on the formation of adolescents' subjectivity in a neoliberal context]. Uruguay: Psicolibros Universitario.

Laplanche, J. (1980). La sexualidad [The sexuality]. Buenos Aires: Nueva Visión.

Maier, H. (1980). Tres teorías sobre el desarrollo del niño [Three theories of child development]. Buenos Aires: Amorrortu.
Nisbet, R. (1996). La formación del pensamiento sociológico [The formation of the sociological thought]. Tomos 1 y 2. Buenos Aires: Amorrortu.

Pavlovsky, E. (1975). Psicodrama psicoanalitico en grupos [Groups' psychoanalytical psychodrama]. Buenos Aires: Kargieman.

Pichon-Rivière, E. (1981). Del psicoanálisis a la Psicología Social [From psychoanalysis to the Social Psychology]. Vols. I y II. Buenos Aires: Nueva Visión.

Urribarri, R. (1990). Sobre adolescencia, duelo y a posteriori [About adolescence, mourning and a posteriori]. Revista Psicoanalítica Argentina, 42(4), 179-181.

Winnicott, D. (1972). Realidad y juego [Reality and playing]. Barcelona: Gedisa.

Winnicott, D. (1981). El proceso de maduración en el niño [The maturational processes in the child]. Environment Barcelona: Laia.

División de Ciencias Sociales y Humanidades Universidad de Guanajuato León, Guanajuato - México

Fecha de recepción: 19 de diciembre de 2011 Fecha de aceptación: 6 de noviembre de 2012 
